\title{
10
}

\section{What Can Ethnography Tell us about Sociolinguistic Variation over Time? Some Insights from Glasgow*}

\author{
Robert Lawson
}

\section{Introduction}

Although a well-established methodological framework in anthropology, criminology, and sociology (Atkinson and Hammersley 2007: 1-10), it has only been over the past 10-15 years that ethnographic methods have seen increased use in (quantitative) sociolinguistics in the UK (see Rampton 2007 for a discussion of linguistics and ethnography in the UK). Scotland in particular has been a key site for research which integrates ethnographic approaches with sociolinguistic investigations of language use and linguistic variation and change in a variety of contexts. This has included research on community organisations (Clark 2009; Clark and Trousdale 2009), Gaelic communities (McEwan-Fujita 2010; Smith-Christmas 2012), national parliaments (Shaw 2009-2011), rural communities (Thomson 2012), schools (Alam 2007; Lambert, Alam and Stuart-Smith 2007; Lawson 2009; Nance 2013), sports clubs (Wilson 2007), and the workplace (Eustace 2012).

Ethnographically informed sociolinguistic research has been central to advancing our understanding of the intersection of linguistic variation and social meaning (Eckert 2000). Moreover, it has raised the importance of augmenting our sociolinguistic analyses by attending to the locally embedded and contextually dependent knowledge of speakers' social positions, relationships, and so on. There is, however, a distinct lack of reflexive accounts of the potential limitations of ethnography in explaining why certain speakers produce the patterns of variation that they do.

In addressing this issue, this chapter outlines a phonetic analysis of conversational data collected during a period of long-term ethnographic fieldwork in Banister Academy, ${ }^{1}$ a high school in Glasgow, Scotland. In particular, my analysis focuses on the extent to which an ethnographic understanding of three speakers' social movements (Mark, Neil, and Peter) can offer a deeper insight into speaker variation of the CAT vowel (equivalent to Wells' 1982 TRAP/BATH/PALM set; Johnston 1997). As such, this chapter also contributes to the ongoing discussion regarding the role of the individual in 
accounts of linguistic variation (cf. Eckert 2005; Moore 2010; Stuart-Smith and Timmins 2010), while also furthering our understanding of locally situated processes of linguistic variation in Scotland.

In the next part of the chapter, I outline the background of ethnographic research, tracing the field from its historical roots in anthropology through to its more recent position within sociolinguistics. I then briefly discuss some of the issues inherent in using ethnography as a research tool and the key advantages and disadvantages of utilising ethnographic methodology in the analysis of language variation and change (focusing on ethnographic sociolinguistic studies within the Scottish context). In the analysis section, I present a case study of linguistic variation in Banister Academy, focusing particularly on realisations of the CAT vowel across the three speakers, and discuss these results in light of the ethnographic fieldwork conducted in the school. Lastly, I conclude the chapter with some general points regarding the scope and limitations of ethnographic accounts of speaker variation.

\section{What is ethnography?}

Ethnography has been variously defined as the 'study of people in naturally occurring settings or "fields" by means of methods which capture their social meanings and ordinary activities' (Brewer 2000: 10), as a 'descriptive account of a community or culture' (Atkinson and Hammersley 2007: 1), as the 'systematic approach to learning about the social and cultural life of communities, institutions and other settings' (LeCompte and Schensul 2010: 1), and as a 'qualitative social science practice that seeks to understand human groups (or societies, or cultures, or institutions)' (Madden 2010: 16). What ties all of these definitions together is their focus on understanding the lived reality of people in normal, everyday settings.

The beginnings of ethnography as a separate and distinct method within the field of anthropology can be traced back to the seminal work of anthropologists Franz Boas and Bronislaw Malinowski at the turn of the twentieth century. Malinowski's and Boas' research, on the Kula tribe of Papua New Guinea and the Inuit of Baffin Island respectively, started a long tradition of anthropologists conducting ethnographies of supposedly 'exotic' cultures, a tradition closely tied to the demands of an expanding British Empire which wanted to study (and later exploit) those cultures it was attempting to colonise (Pels 1997: 164; Brewer 2000: 11). Indeed, the aim of early ethnographic work was typically to chart and describe a range of sociocultural phenomena among indigenous cultures, including detailed descriptions of agriculture, art, the political system, kinship, superstitions, gift-giving, reciprocity arrangements, local ecology, trade, and so on. In order to better understand these phenomena, ethnographers used a range of methods, including field notes, interviews, photography, sketches, maps, recordings of songs and myths, and importantly, participant observation. 
The last of these, participant observation, is considered key to the pursuit of ethnographic knowledge, where ethnographers attempt to integrate themselves as fully as possible into the community being studied, sometimes for a period of several years. Through such integration, the aim is for the researcher to better understand social phenomena from the perspective of the participants involved in the research. This stance is effectively summed up in Malinowski's major contribution to ethnographic theory and method, Argonauts of the Western Pacific, in which he argues that the point of ethnography is 'to grasp the native's point of view, his relation to life, to realize his vision of his world' (Malinowski 1922, republished in 1984: 25).

\section{A brief history of ethnography in language research}

The study of language was a central part of early ethnographic work, particularly in the pioneering research of early anthropologists such as Franz Boas, Edward Sapir, and Benjamin Lee Whorf (what Duranti 2003: 324 calls the 'first paradigm' of language as culture research). The field of 'anthropological linguistics', however, focused mainly on the use of linguistics as a tool for the analysis of culture and history, language documentation, and the relationship between language, culture and the mind (Duranti 2003: 326), rather than the formal investigation of how language was used in context. Drawing on developments in the concurrent field of linguistics, Dell Hymes was one of the first to rename the field 'linguistic anthropology', a name which highlighted its independence from the field of linguistics while simultaneously reaffirming its anthropological roots.

This 'rebranding' of the field marked a shift to the second paradigm of language research within anthropology through a focus on language use across different speakers, contexts and activities. In particular, Hymes' work on the 'ethnography of communication' (originally the 'ethnography of speaking', Hymes 1964, 1974), contested Chomsky's claim that the aim of linguistic theory was to better understand and model a speaker's linguistic competence (a speaker's knowledge about the syntax, morphology, and phonology of a language) by arguing that linguistics should be concerned with a speaker's communicative competence (the social knowledge which speakers bring to bear during interactions). While Chomsky's position relied on intuitive data from a fictional 'ideal speaker-listener in a completely homogeneous speech-community' (Chomsky 1965: 3), the ethnography of communication emphasised that insights into the nature of language could only be reliably inferred through data collected from actual speakers.

Almost simultaneously, a focus on real-life language data coupled with ethnographic approaches was emerging within the newly coined field of sociolinguistics, including Labov (1963), Hymes (1964, 1974), and the collected chapters in Gumperz and Hymes (1986). In a 'perfect storm' of circumstances, both Hymes and Labov started working at the University of Pennsylvania 
(Hymes in 1965 and Labov in 1971), leading to a fervent intellectual environment where the 'study of language as used in social life gained momentum' (Duranti 2003: 328), not only within linguistic anthropology, but also sociolinguistics, narrative analysis, and a number of other subfields where the relationship between language and society was of central interest.

From the late 1980s onwards, we see the emergence of the third paradigm, where researchers start to focus on the role played by language in the social construction of class, gender and ethnicity. Rather than viewing language as a reflection of social differences (as had been the case in early sociolinguistic work), researchers began conceptualising language as a way through which social differentiation was constructed (Bucholtz 1997; Eckert 2000; Mendoza-Denton 2008. See also Bucholtz and Hall 2008 for a review of the intersections of these related areas of inquiry). These studies were strongly characterised by their inclusion of ethnographic methods in order to study both the nature of locally embedded language use and the constituent role of language use in the construction of social identity.

\section{So why ethnography?}

As noted above, ethnographic methodology in sociolinguistic research has grown in recent years. In this section of the chapter, I outline some of the reasons why ethnography has become so central to understanding linguistic variation and change, and in particular, issues of language and social meaning, before discussing some of its methodological and analytical limitations.

\section{'Top-down' vs 'bottom-up' categorisation}

One of the defining characteristics of survey-type research is that the categories in which researchers are interested are often already pre-established. In many social science questionnaires, for example, respondents are typically requested to identify themselves in terms of predetermined responses to age, ethnicity, class, sex (or occasionally gender), and so on. These choices are, however, already determined by the researcher or analyst in a 'top-down' fashion and thus imposed as the only choices available to respondents. ${ }^{2}$ In this way, people who participate in this kind of research are ultimately bundled into 'analytical boxes' with no say in how these boxes might (or might not) represent their own social reality. To exemplify the importance of this issue in a more concrete way, it is worthwhile problematising one of the main categories used in sociolinguistic analysis: speaker sex.

In the traditional quantitative sociolinguistic paradigm (e.g. Labov 1966; Trudgill 1974), speaker sex is usually broken into two categories, male and female. Recent scholarly work within queer linguistics (e.g. Barrett 1998; Cameron 2005), however, has identified how such a binary fails to encompass the multitude of ways in which speakers might orientate towards and construct their own notion of biological sex (see also Eckert and 
McConnell-Ginet 2003: 15-31 for a discussion of the socially constructed nature of biological sex). As Eckert and Podesva (2011: 6) note, 'twodimensional categories such as male or female ... offer very blunt socialanalytical instruments', limiting our explanatory and descriptive accounts of how speakers exploit linguistic resources in the construction of identities which might not align with supposedly straightforward notions of male or female (see also Hall 2003: 355-9).

In light of this, ethnography seeks to discover locally relevant, culturally salient and socially important 'ways of being'. Since ethnography does not assume what the relevant social categories are (Eckert 2000: xiv), these ways of being emerge from the bottom up rather than being imposed from the top down. This emic (inside) perspective is an important distinction to the etic (outside) based perspective adopted in traditional quantitative sociolinguistic research. For example, in her ethnography of Scottish Asian speakers in Glasgow, Alam (2007) found that local ways of being among groups of female Asian adolescents in Glasgow were built on participants' alignment with and affiliation to Western versus Eastern ideologies (see also Alam and Stuart-Smith 2011: 217; Alam and Bramwell, this volume). These patterns of distinction manifest themselves through differential deployment of a range of social practices across three different groups, the 'Conservatives', the 'Moderns', and the 'Messabouts'. Girls more closely orientated towards Eastern ideologies (the Conservatives) adhered to traditional Pakistani values and practices, such as wearing headscarves and rejecting make-up and jewellery, while those girls more closely orientated to Western ideology (the Moderns and the Messabouts) dated, did not wear headscarves, and were more likely to talk about future career plans and aspirations. At a local level, ways of enacting and constructing 'Pakistani' identity in this Glasgow high school were more nuanced and more particular than a 'top-down' category of 'Pakistani Asian'. As Eckert and Podesva (2011: 6) argue, although categories remain important for the purposes of sociolinguistic analysis, it is important that 'categories be ethnographically significant [and that] they be viewed as products of, rather than explanations for, variation patterns'. In the next section, I discuss in more detail how the discovery of locally relevant categories has important ramifications for how we approach the construction of social identity.

\section{The contribution of ethnography to understanding social identity}

Over the past 20 years, sociolinguistics has been strongly focused on the intersection of linguistic variation and the construction of social identity (defined here as 'the social positioning of self and other', Bucholtz and Hall 2005: 586). Departing from traditional conceptualisations of identity categories (such as class, age, ethnicity, and so on), researchers working within the ethnographic framework argue that social identity is something which speakers do, rather than something they simply have (Eckert 2000: 42). As 
such, speakers construct themselves as young or old, male or female, working class or middle class (and intersections thereof), ${ }^{3}$ instead of just being young or old, male or female, working class or middle class. Language is one of the key vectors through which people construct their social identities, as particular 'kinds of people' (Eckert and McConnell-Ginet 1995: 469). Since ethnographic sociolinguistics shifts the focus from a 'top-down' to a 'bottom-up' perspective of the social structures in which language exists, allowing us to develop a more accurate picture of the kinds of identities which speakers construct, it is possible to develop a more nuanced understanding of how language functions as a constituent part of social differentiation and identity, rather than as a reflection of macro-social categories such as gender, class, and ethnicity (Bucholtz and Hall 2008: 409).

For example, while Alam (2007) found that the female pupils in her fieldwork site had different orientations towards Eastern and Western ideologies, the analysis demonstrated that linguistic practice was central to how the girls indexed these orientations. More specifically, speakers who identified most closely with a traditional Pakistani ideology were more likely to utilise postalveolar variants of $/ \mathrm{t} /$ and /d/ while those who did not were more likely to use alveolar variants (Lambert et al. 2007; Alam and Stuart-Smith 2011). The roles played by variants of / $t /$ and /d/ in the construction of social identity among this particular group of speakers would have been missed if a traditional quantitative sociolinguistic approach had been adopted (see also Lawson, forthcoming for further discussion of this point). Similarly, in a recent study of a pipe band in Fife, Scotland (Clark 2009, this volume; Clark and Trousdale 2009), locally specific demarcations within the pipe band were uncovered through ethnographic fieldwork which allowed for a far more nuanced understanding of how variants of (th) were related to speakers' construction of social identity. Speakers who were identified as 'young' and/or 'tough' were among the leaders of TH-fronted variants of (th), while those speakers who were characterised as mature and senior in authority tend to use higher rates of the standard variant [ $\theta$ ] (Clark 2009: 155-9; see also Lawson, forthcoming for a discussion of TH-fronting in relation to 'tough' masculinity in Glasgow). Again, ethnographic knowledge allowed for a finer degree of social granulation than is normally available through the use of traditional macro-categories such as class, age, gender, and ethnicity.

While these studies focus on fine-grained phonetic variation, ethnographic knowledge can also augment our analysis of other linguistic phenomena. For example, Eustace (2012) demonstrates how ethnographic knowledge can help us make sense of the kinds of style-switching and styleshifting practices speakers deploy in their construction of workplace and professional identities. Drawing on ethnographic data collected from speakers working in the retail service sector in Glasgow, her analysis outlines how speakers make sense of the ideological associations indexed by Glaswegian and Scottish Standard English (SSE), and how the strategic deployment of 
Glaswegian and SSE lexical and grammatical features allows speakers to construct their identities as 'posh' and 'formal' or as 'friendly' and 'informal', depending on the interactional context.

\section{Focus on the individual}

What distinguishes many of the above studies from earlier sociolinguistic research (e.g. Labov 1966) is not only the way in which the idea of social identity is conceptualised, but that there is also a strong focus on individual speakers. Although Eckert (2005: 17) notes that linguists are sometimes 'nervous about studying individuals', recent ethnographic sociolinguistic work has focused its analytical gaze squarely on individual speakers, both as brokers and transmitters of linguistic change (Moore 2010; Clark, this volume) and as interesting stylistic icons in their own right (Podesva 2007). In their analysis on media effects and language change in Glaswegian, StuartSmith and Timmins (2010: 40) make the point that

individuals are inevitably at the heart of language variation and change, because it is the conscious or (more usually) subconscious adjustments in individuals' linguistic behaviour which constitutes variation, and potentially change.

In a sense, the focus on the individual is a natural part of the focus on social meaning and the construction of social identity, since it is at the level of individual language use that identities are constructed and meaning negotiated. Moreover, by ignoring individuals, sociolinguistic description is reduced to large group means and disembodied accounts of how language is actually used on the ground.

\section{Problems and disadvantages}

From the discussion above, it should be clear that ethnography contrasts markedly with the 'positivist' research tradition, a paradigm which investigates human behaviour through the deployment of controlled laboratory tests, survey questionnaires and other quantitative research tools, ${ }^{4}$ where the primary focus is on replicable and reproducible results (Atkinson and Hammersley 2007: 5-9). As such, ethnography is sometimes unfairly characterised as 'unscientific' (Rengert 1997), and in particular, that it lacks the reliability and replicability of more established scientific methods. Writing about the use of ethnography within the field of medical informatics, Forsythe (1999: 131) addresses a number of common assumptions about ethnography and offers a robust defence of the apparently 'unscientific' nature of ethnographic enquiry:

[A]nthropologists see ethnographic work as technical in nature and take seriously issues of methodological appropriateness, procedure, 
and validity. Proper ethnography involves systematic method and epistemological discipline, neither of which is seen by anthropologists as necessarily requiring rigid adherence to preformulated research protocols.

Researchers working within an ethnographic paradigm have argued that not only is ethnography scientific and investigative, but that the business of ethnographic research can be positioned more squarely within traditional conceptualisations of 'science', 5 including attention to hypothesis testing (Agar 1996) and generalisation (Brannen 2011). Moreover, ethnographers use well-established and rigorous data collection methods to develop a better understanding of social phenomena from the perspective of the research participants (Herbert 2000: 558-60; LeCompte and Schensul 2010: 1), and a large number of introductory textbooks have tackled the issue of reliable data collection methods, systematic transcription and analysis, and grounded theoretical description, all of which work in tandem to allow the ethnographer to develop 'thick description' (Geertz 1973), rather than just being 'a walking tape recorder' (Forsythe 1999: 140).

Other criticisms of ethnography centre on resources, particularly the issue of time. Indeed, ethnographic studies can often involve protracted periods in the field, sometimes for several years. For example, in his ethnographic study of gangs in East Harlem, Bourgois (2003) describes how he moved into the local neighbourhood for three years so he would have better access opportunities to key informants. Spending so long doing fieldwork is a critical component of ethnography, primarily due to the need to establish meaningful relationships with people in the community. Such investments of time are, however, typically not possible except during postgraduate study (or when the principal fieldworker is the recipient of a large research grant).

\section{Ethnographic sociolinguistics in Scotland: a case study}

While the analysis of linguistic change over time (particularly over the lifespan, Sankoff and Blondeau 2007; Bowie 2010) is a well-researched area of study, the study of how changes in social identity over time are realised in linguistic terms is a relatively unexplored area of sociolinguistic enquiry (cf. Moore 2010; Stuart-Smith and Timmins 2010). In the next section of the chapter, I present a case study of an ethnography conducted between 2005 and 2007 of a high school in Glasgow named Banister Academy. In particular, I concentrate on the social movements of three speakers (Mark, Neil, and Peter) and examine the extent to which changes (or lack thereof) in their social identity are accompanied by changes in linguistic practice. In essence, the aim is to outline how longitudinal changes in group membership in Banister Academy can be mapped onto specific patterns of linguistic 
variation. Before presenting the results of the linguistic analysis, I first describe the ethnographic context of Banister Academy and the speakers considered in this chapter.

\section{Ethnography of Banister Academy}

Banister Academy is a high school in Glasgow with an enrolment of 700 students. Over the course of the fieldwork, I attended the school approximately three days a week (for a detailed discussion of ethics and data collection, see Lawson 2009, 2011). Like most school ethnographers (cf. Eckert 2000: 75), I spent most of my time wandering around while the pupils were in class, and conducted most of the recordings and ethnographic observation during break times and lunchtimes. During the early part of the fieldwork, I noticed that pupils appeared to belong to different groups and participated in different activities.

As several researchers have noted (Eckert 2000: 77; Tagliamonte 2006: 24; Eckert and Podesva 2011: 6), a key step in sociolinguistic analysis is to determine which speakers belong to which group, since identifying salient social groupings is a prerequisite to understanding the intersection between group membership and linguistic variation. First, then, was the decision to use an appropriate theoretical framework which would allow the kinds of social structures I observed in Banister Academy to be accounted for. Since social groups (particularly adolescent groups) tend to be delimited along axes other than language use, it did not make sense to use the well-established theoretical structures of either the speech community or the social network (Eckert 2000: 32; Lawson 2011: 230). Indeed, my initial ethnographic observations had identified that speakers organised their social groupings according to a range of social practices (Lave and Wenger 1991), including dress, musical taste, orientation towards the school, hobbies and so on. Thus, it made sense to adopt a framework within which the idea of 'practice' is central: the 'community of practice' (CofP).

This framework was first integrated into sociolinguistics (particularly ethnographic sociolinguistics) in an influential article by Penny Eckert and Sally McConnell-Ginet (1992). In this article, they define a community of practice as a group of people who create shared social practices in the pursuit of a common goal of some sort (Eckert and McConnell-Ginet 1992: 464). Part of the argument advanced by Eckert and McConnell-Ginet was the call for sociolinguists to treat linguistic variation as a way through which speakers construct social differentiation, rather than seeing linguistic variation as a reflection of social differences. Taking this perspective means that language becomes a social practice which speakers exploit in the construction of their identities. By contrast, the prevailing view within traditional Labovian sociolinguistic research was that if a particular variant was used more regularly by male speakers, it was because the speakers were male. Eckert and McConnell-Ginet's position is in sharp contrast to the view that speakers 
are simply passive reproducers of particular class, age, or ethnicity-based language patterns and that speakers use certain variants simply by virtue of being young/old, male/female, middle class/working class.

The second step towards determining which speakers belonged to which CofP was the method of social 'triangulation' (Mendoza-Denton 2008: 240) which combined self-identification by speakers, other-identification by peers, and my own ethnographic observation of social interactions, social groupings and shared social practices. This approach was primarily motivated by the fact that many of the pupils in Banister Academy tended not to view themselves as belonging to a group or clearly delimited category, but rather as someone who did not claim any sort of group affiliation. Indeed, in the first few months of fieldwork, questions such as 'what group would you say you were in?' were often met with answers like 'I wouldn't really say that I'm part of a group' or 'I'm just me, I'm just normal'. The complicating factor, however, was that my own ethnographic observation uncovered significant clustering of shared social practices and mutual engagement in tasks, which contradicted claims that a particular speaker did not identify with a particular group. Additionally, pupils in Banister Academy would often comment on their perceived social categorisation of other pupils. If self-identification had been the only criterion used to establish CofP membership, it is highly probable that there would have been only one large group of 'normal' pupils, a situation at odds with what was being observed during the fieldwork. In order to reconcile the apparently conflicting degrees of social information, it was necessary to use triangulation from different sources to help determine social group membership.

Once these steps were taken, I could start to consider who belonged to which CofP, and to begin to identify the kinds of social groupings which were emerging. Over the course of the fieldwork, four CofPs were identified which I named the Alternative, Sports, 'Ned' and Schoolie CofPs. ${ }^{6}$ These CofPs were met at different times of the fieldwork and membership was continually changing due to the shifting patterns of friendship and group allegiance which characterises many high school social settings.

For the purposes of this chapter, I will be discussing in more detail three speakers, Neil, Mark and Peter. Neil and Mark were members of the Alternative and Sports CofPs respectively, while Peter 'floated' between the Alternative and Sports CofPs in Year 1 before settling as a core member of the Alternative CofP in Year 2 onwards.

The Alternative CofP was one of the first groups I encountered during my fieldwork at Banister Academy, and from these initial meetings, it was clear that their social practices could be considered 'alternative' rather than 'mainstream'. For example, they rejected a number of popular sports (primarily football and rugby), and instead preferred sports such as BMX riding and American wrestling. Similarly, their musical tastes were more aligned with rock and metal bands such as Nirvana, Cradle of Filth, Iron Maiden, 
Metallica and Slipknot. Importantly, their clothing choices reflected these social practices, and many members wore t-shirts branded with their favourite band or wrestling icon. More 'extreme' members wore black leather coats and biker boots instead of the sports jackets and trainers preferred by other CofPs.

By contrast, the Sports CofP were more 'mainstream', and my first ever interaction with the members of this CofP was through being invited to play a game of football with them one lunchtime. Sports emerged as an important activity among the members, with football in particular being a key mutual endeavour carried out every break time and lunchtime. In order to facilitate their sporting pursuits, the Sports CofP members generally wore trainers, school jumper with a t-shirt, or a white shirt, either with or without the school tie. None of the members of the Sports CofP wore the school blazer and instead wore a regular jacket over their uniform.

In the first year of the fieldwork, Peter emerged as particularly interesting due to his mobility between both the Sports and the Alternative CofPs. He socialised with both groups regularly and was particularly valued among the Sports CofP for his size, something which was regularly touted as an advantage in sports such as rugby. He also, however, started playing in a heavy metal band, and towards the end of Year 1, began transitioning more fully into the Alternative CofP. By the end of the fieldwork, Peter was regarded as one of the core members of the Alternative CofP, having almost fully given up his association with members of the Sports CofP.

Since linguistic practice is a constituent element of social identity, one hypothesis would be that as a speaker's social identity changes, their pattern of linguistic variation also changes (Moore 2003: 234-9; Mendoza-Denton 2008: 208). Given that Neil and Mark were stable members of the Alternative and Sports CofPs respectively (that is, they were still considered members of these CofPs at the conclusion of the fieldwork and their social practices throughout the ethnography appeared to be consistent), but Peter's CofP membership was changeable, we can compare and contrast how far changes in linguistic practice coincide with changes in social practice and specific substantiations of social identity.

\section{Method}

In order to investigate if patterns of linguistic variation were influenced by changes in social identity, an acoustic analysis of the CAT vowel was conducted on interview data collected during the fieldwork (see Lawson 2013 for a discussion of 'interview' approaches). The CAT set covers Wells' lexical sets of TRAP/BATH/PALM (Wells 1982), but since Scottish English does not have a distinction between minimal pairs like Pam and palm, Johnston (1997) argues for a single lexical set named CAT for specific reference to Scottish English. As I have shown elsewhere, phonetic variation in CAT is related to 
CofP membership, with the Alternative and Sports CofP speakers tending towards relatively raised and retracted realisations (Lawson 2011), thus it was sensible to investigate this variable in more detail to determine whether production of this variable by the three speakers outlined above altered over the course of the fieldwork in line with changes (or lack thereof) in their constructions of social identity.

The acoustic analysis was conducted using Praat (Boersma and Weenick 2013), and $\mathrm{F}_{1}, \mathrm{~F}_{2}$ and $\mathrm{F}_{3}$ measurements were taken at the midpoint of the vowel in every token of CAT produced by Peter, Mark and Neil over the three years of data. These values were then normalised using the Bark Difference Method ${ }^{7}$ to produce an $x / y$ Cartesian coordinate from two measurements, $Z_{3}-Z_{1}$ (equivalent to $F_{1}$, vowel height) and $Z_{3}-Z_{2}$ (equivalent to $F_{2}$, vowel fronting/retraction). For ease of reference, I use the typical $F_{1} / F_{2}$ axis in the discussion below, rather than the normalised Bark values.

Approximately 2000 individual tokens were measured, although since the individual speaker distributions have a degree of overlap, only speaker means are presented below (Lawson 2011). The data were also subject to a mixed-effects linear regression analysis using Rbrul (Johnson 2009). Unlike traditional fixed-effects models (e.g. GoldVarb), mixed-effects models control for both 'random' effects (like speaker and token type), as well as 'fixed' effects (like preceding phonological environment and CofP membership) in determining which factors most influence the observed variation. As such, models derived from a mixed-effects approach are generally more robust than those derived from a fixed-effects model. Although Peter was a 'floater' in Year 1 and an 'Alternative' in Years 2 and 3, for the purposes of this chapter, Peter was assigned to a 'floater' CofP for all three years of data (primarily to see whether his behaviour was distinct from the other two speakers), while Neil and Mark were assigned to the 'Alternative' and 'Sports' CofPs respectively. Word was included as a random factor (for further discussion of Rbrul and mixed-effects modelling, see Johnson 2009; Drummond 2011; Brato, this volume; Clark, this volume). In the statistical analysis, positive coefficients for $F_{1}$ correspond to raised vowels while negative coefficients correspond to lowered vowels. Positive coefficients for $\mathrm{F}_{2}$ correspond to retracted vowels while negative coefficients correspond to fronted vowels. Additionally, since the data violate the assumptions of a normal distribution required for an analysis of variance test (ANOVA), a Kruskal-Wallis test was also conducted to determine whether the differences between each year of data for each speaker were statistically significant or not (cf. Field 2009: 559-77). The results of both these statistical analyses are reported below.

\section{Analysis}

Figure 10.1 shows the position of the CAT vowel relative to both BET and COT (roughly equivalent to the DRESS and THOUGHT lexical sets) across the 


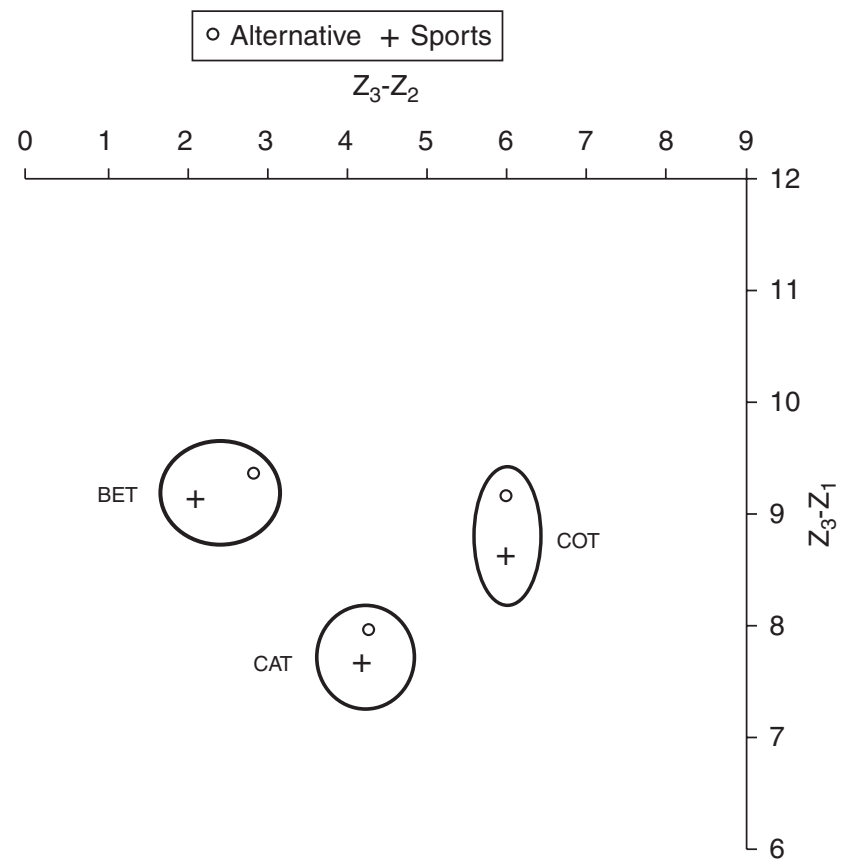

Figure 10.1 Distribution of three Glaswegian vowels: BET, CAT, COT

Alternative and Sports CofPs. As can be seen, Alternative CofP speakers generally produce a more raised CAT vowel than Sports CofP speakers (the means above are derived from all the members of the Alternative and Sports CofPs, and thus may not reflect the individual results reported below. See Lawson 2011 for a more detailed discussion of CAT variation and CofP membership).

Focusing on CAT, Figure 10.2 outlines the pattern of variation across the three years of data for all three speakers (although no data were collected from Neil in Year 2). In terms of the overall distribution, we can see that there does appear to be a change in both Peter and Mark's overall production of CAT over the course of the fieldwork. In particular, both speakers produce more raised realisations in Years 2 and 3, with almost no change in the degree of fronting/retraction. Neil, on the other hand, has very similar patterns of variation in Year 3 compared to Year 1, suggesting that he did not vary his pronunciation of this variable to the same extent as Mark and Peter.

The statistical analysis of $\mathrm{F}_{1}$ (vowel height) shows that 'CofP membership' was significant (Table 10.1), with Neil (Alternative CofP) lowered and both Mark (Sports) and Peter (Floater) raised. The factor group of 'year' also emerges as a significant predictor of variation, with lowered realisations in Year 1 and more raised realisations in Years 2 and 3, particularly for Mark 


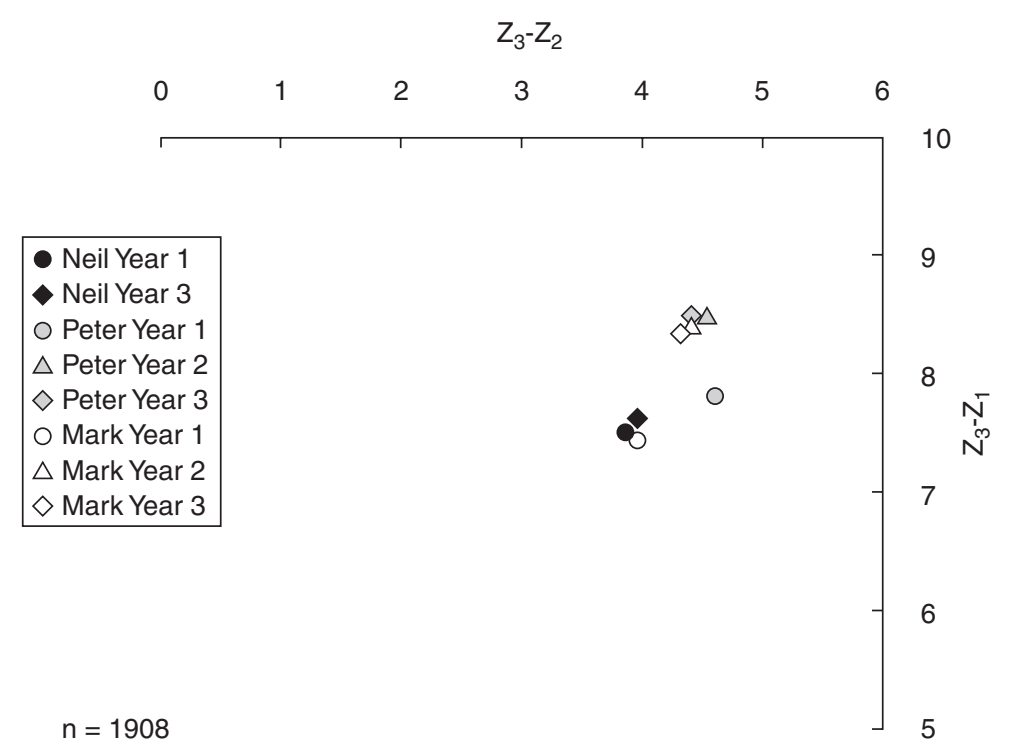

Figure 10.2 Distribution of CAT across three speakers

Table 10.1 Mixed-effects model of CAT $\mathrm{F}_{1}$ with significant predictors across three speakers

\begin{tabular}{llrrr}
\hline Variable & Factor & Tokens & $\boldsymbol{\beta}$ & Mean \\
\hline CofP membership & Alternative & 517 & -0.436 & 7.598 \\
$p<0.01$ & Floater & 865 & 0.334 & 8.408 \\
& Sports & 514 & 0.101 & 8.233 \\
Year & Year 1 & 289 & -0.430 & 7.591 \\
$p<0.01$ & Year 2 & 505 & 0.269 & 8.454 \\
& Year 3 & 1102 & 0.161 & 8.139 \\
Also significant & Topic & & & \\
Not significant & Preceding phonological class, following phonological class, \\
& number of syllables & & \\
Random effects & Word & & & \\
Model & Deviance = 4179.95 df = 23 intercept = 7.960 mean $=8.140$ \\
\hline
\end{tabular}

and Peter. For linguistic constraints, 'topic' (not included in Table 10.1 due to the large number of factor levels) was the only factor returned as significant, suggesting that particular types of topic influenced vowel raising/ lowering (although this is not discussed further here).

A Kruskal-Wallis test (Table 10.2) reported statistically significant differences in $F_{1}$ between the Year 1 and Year 2/3 data for both Mark and Peter, with relatively large chi-square values being returned ( $\chi^{2}$ is used to determine how much variance the model accounts for). No statistically 
Table 10.2 Kruskal-Wallis analysis of CAT $\mathrm{F}_{1}$ across three speakers (statistically significant results are marked*)

\begin{tabular}{|c|c|c|c|c|}
\hline Speaker & Years compared & Tokens & $\chi^{2}$ & $p$ \\
\hline Neil & $\begin{array}{l}1 \sim 2 \\
1 \sim 3 \\
2 \sim 3\end{array}$ & $\begin{array}{c}- \\
518 \\
-\end{array}$ & $\begin{array}{c}- \\
1.904 \\
-\end{array}$ & $\begin{array}{c}- \\
0.168 \\
-\end{array}$ \\
\hline Peter & $\begin{array}{l}1 \sim 2 \\
1 \sim 3 \\
2 \sim 3\end{array}$ & $\begin{array}{l}304 \\
670 \\
774\end{array}$ & $\begin{array}{r}46.761 \\
59.725 \\
0.133\end{array}$ & $\begin{array}{r}{ }^{*} 0.000 \\
{ }^{*} 0.000 \\
0.715\end{array}$ \\
\hline Mark & $\begin{array}{l}1 \sim 2 \\
1 \sim 3 \\
2 \sim 3\end{array}$ & $\begin{array}{l}395 \\
212 \\
425\end{array}$ & $\begin{array}{r}77.255 \\
58.436 \\
0.546\end{array}$ & $\begin{array}{r}{ }^{*} 0.000 \\
{ }^{*} 0.000 \\
0.460\end{array}$ \\
\hline
\end{tabular}

Table 10.3 Mixed-effects model of CAT $\mathrm{F}_{2}$ with significant predictors across three speakers

\begin{tabular}{|c|c|c|c|c|}
\hline Variable & Factor & Tokens & $\beta$ & Mean \\
\hline \multirow{3}{*}{$\begin{array}{l}\text { CofP membership } \\
p<0.01\end{array}$} & Alternative & 517 & -0.239 & 3.938 \\
\hline & Floater & 860 & 0.213 & 4.442 \\
\hline & Sports & 512 & 0.026 & 4.304 \\
\hline \multirow{3}{*}{$\begin{array}{l}\text { Year } \\
p<0.01\end{array}$} & Year 1 & 283 & -0.172 & 4.105 \\
\hline & Year 2 & 504 & 0.148 & 4.454 \\
\hline & Year 3 & 1102 & 0.024 & 4.223 \\
\hline \multirow{6}{*}{$\begin{array}{l}\text { Following phon. class } \\
p<0.01\end{array}$} & Glottal & 572 & 0.198 & 4.465 \\
\hline & Vowel & 33 & 0.119 & 4.581 \\
\hline & Voiced obstruent & 166 & 0.032 & 4.374 \\
\hline & Voiceless obstruent & 547 & 0.012 & 4.235 \\
\hline & Approximant & 55 & -0.143 & 4.402 \\
\hline & Nasal & 516 & -0.218 & 4.011 \\
\hline \multirow{5}{*}{$\begin{array}{l}\text { Preceding phon. class } \\
p<0.01\end{array}$} & Vowel & 214 & 0.155 & 4.355 \\
\hline & Nasal & 221 & 0.053 & 4.466 \\
\hline & Voiceless obstruent & 511 & 0.009 & 4.196 \\
\hline & Glottal & 14 & -0.006 & 3.913 \\
\hline & Voiced obstruent & 494 & -0.044 & 4.209 \\
\hline Also significant & \multicolumn{4}{|l|}{ Topic } \\
\hline Not significant & \multicolumn{4}{|l|}{ Number of syllables } \\
\hline Random effects & \multicolumn{4}{|c|}{ Word } \\
\hline Model & \multicolumn{4}{|c|}{ Deviance $=3936.692 \mathrm{df}=33$ intercept $=4.27$ mean $=4.267$} \\
\hline
\end{tabular}

significant difference, however, is reported for Neil's Year 1 Year 3 data, and there were no statistically significant differences for Year 2 Year 3 for either Mark or Peter.

To turn now to $\mathrm{F}_{2}$ (vowel fronting/retraction), the first significant factor is 'CofP' (Table 10.3), although the coefficients are much lower than those for $\mathrm{F}_{1}$, suggesting a smaller effect size overall. 'Year' is also returned as a 
Table 10.4 Kruskal-Wallis analysis of CAT $\mathrm{F}_{2}$ across three speakers (statistically significant results are marked $^{*}$ )

\begin{tabular}{|c|c|c|c|c|}
\hline Speaker & Years compared & Tokens & $\chi^{2}$ & $p$ \\
\hline Neil & $\begin{array}{l}1 \sim 2 \\
1 \sim 3 \\
2 \sim 3\end{array}$ & $\begin{array}{c}- \\
518 \\
-\end{array}$ & $\begin{array}{c}- \\
1.904 \\
-\end{array}$ & $\begin{array}{c}- \\
0.168 \\
-\end{array}$ \\
\hline Peter & $\begin{array}{l}1 \sim 2 \\
1 \sim 3 \\
2 \sim 3\end{array}$ & $\begin{array}{l}304 \\
670 \\
774\end{array}$ & $\begin{array}{l}0.070 \\
4.753 \\
5.906\end{array}$ & $\begin{array}{r}0.792 \\
* 0.029 \\
* 0.015\end{array}$ \\
\hline Mark & $\begin{array}{l}1 \sim 2 \\
1 \sim 3 \\
2 \sim 3\end{array}$ & $\begin{array}{l}395 \\
211 \\
425\end{array}$ & $\begin{array}{r}19.167 \\
13.603 \\
0.227\end{array}$ & $\begin{array}{r}{ }^{*} 0.000 \\
{ }^{*} 0.000 \\
0.634\end{array}$ \\
\hline
\end{tabular}

significant predictor, with more fronted realisations in Year 1 than in Years 2 or 3. In terms of linguistic constraints, 'following phonological context', 'preceding phonological context' and 'topic' all returned as significant (although see comment about 'topic' above). $\mathrm{F}_{2}$ is more retracted if it is preceded by a vowel or followed by a glottal, and more fronted if preceded by a voiced obstruent or followed by nasal.

The Kruskal-Wallis test (Table 10.4) reported no statistically significant differences in $\mathrm{F}_{2}$ across the data for Neil. For Peter, we can see that there is no statistically significant difference for Year 1 Year 2 (this makes sense given that Peter's mean $F_{2}$ values for Years 1 and 2 are almost the same). A statistically significant difference emerges for Year 1 Year 3 and Year 2 Year 3 ( $p$-value $=0.029$ and 0.015 respectively), even though the differences in degree of fronting/retraction (according to the means at least) appear to be minimal. For Mark, a significant difference is reported for Year 1 Year 2 and for Year 1 Year 3, although not for Year 2 Year 3. Given the slight retraction in Years 2 and 3, this finding is unsurprising.

\section{Summary of results}

It appears to be the case that most of the differences across the three years of data can be attributed to a change in vowel height $\left(\mathrm{F}_{1}\right)$. More specifically, both Peter and Mark produced raised realisations of CAT in Years 2 and 3 compared to Year 1 , while Neil remains relatively stable with lowered realisations across Years 1 and 3.

So how do we make sense of these results by appealing to the ethnographic data? To what extent can ethnographic knowledge shed light on how changes in a speaker's social identity are accompanied by changes in linguistic practice? And what are the potential limits of how useful ethnographic knowledge is in explaining the observed patterns? 


\section{Using ethnography to make sense of variation}

It was noted above that in Year 1, Peter socialised with members of both the Alternative and Sports CofPs. Crucially, his peripheral membership within the Alternative CofP meant that he was ideally placed to 'learn' the appropriate social practices associated with the Alternative CofP. Indeed, for an individual to learn the relevant social practices within a particular CofP, they must have access and opportunity to interact with individuals who actually use these practices (Eckert and Wenger 2005). Since Peter interacted with the Alternative CofP in a restricted form by virtue of his 'floater' status in Year 1, he had the opportunity to observe and participate in many of the social practices which constituted an Alternative style. In Year 2, Peter begins his transition away from being a peripheral member of the Alternative CofP, and in Year 3, he completes his journey from peripheral to core member. This social change was correspondingly accompanied by significant alterations in Peter's personal style. For example, in the second and third year of the fieldwork, he grew his hair long, wore markedly 'Alternative' clothing (black hooded jackets, branded t-shirt, silver jewellery, and so on), spoke more openly and more often about his musical tastes, associated less with his friends in the Sports CofP, and started playing drums for a local heavy metal band. Peter's transition to the Alternative CofP is highlighted in the following excerpt.

1 Peter: [Ray is] more than last year for a start. He's basically more gothic since-

I've actually interested [Ray] in a couple of bands, it's quite fun.

5 RL: Uh-huh, so youRay: Aye, eh, (inaudible), kidding on.

RL: $\quad$ So you introduced him to?

Peter: I've introduced [Ray] to more heavier stuff than what he used to listen to.

10 RL: Uh-huh.

Ray: (inaudible) Neil introduced me-

Peter: Eh, no, Lamb of God was yours right but, see the other bands I've got into some heavier-

Ray: (inaudible)

15 Peter: I got you into heavier stuff, like, Devilmoon and stuff, like pure metal.

The above excerpt outlines both Peter and Ray's explicit social awareness that Peter is now a 'trend setter'. By becoming a point of orientation for other members of the Alternative CofP, Peter is able to determine the 
kinds of social practices in which someone should engage to become 'more gothic', ultimately issuing advice to other people on 'how to be Alternative' (cf. McConnell-Ginet 2008: 506) and establishing new social practices (Eckert and Wenger 2005).

What is intriguing is that the change in Peter's construction of social identity (and consequently his social practices) is simultaneously accompanied by a change in his linguistic practices. Indeed, the largest difference between the two $F_{1}$ values of CAT is between Years 1 and 2, with this difference becoming markedly smaller between Years 2 and 3 . This suggests that as his social identity stabilised, his linguistic variation followed suit. What is somewhat surprising, however, is that Peter's pattern of variation does not converge towards Neil, even though Neil remained a core Alternative member for the duration of the fieldwork. One possible reason for this is that Peter's understanding of the vowel height which characterises the Alternative CofP is higher than the understanding held by other members of the group. As a result, he hypercorrects the 'target' pronunciation of CAT, and indeed, Peter does produce the most raised pronunciation of CAT out of all the Alternative speakers analysed across the data set (cf. Lawson 2011: 244-5).

In comparison, Neil and Mark both maintained their social identities as Alternative and Sports CofP members respectively. While data were collected from Neil only for Years 1 and 3, the analysis showed that his pattern of variation for CAT over these two time points did not change, on either the $\mathrm{F}_{1}$ or $\mathrm{F}_{2}$ axis. Since his social identity was stable, the consistent patterning of CAT is expected.

Mark, however, appears to be a relative outlier compared to Peter and Neil. Mark maintained his social identity as a Sports CofP member for the duration of the fieldwork, yet the analysis shows a large shift in his realisation of САT between Years 1 and 2 which then settles down between Years 2 and 3. Although this pattern is very similar to Peter's, it is an unexpected one. We have to ask, then, why a stable social identity manifests in two different patterns of variation.

The most plausible explanation is that Mark somehow changed in a way which was not able to be determined during the ethnography. If he was constructing a different social identity outside of the fieldwork site, but bringing aspects of it into the school, it was an invisible process to me as an ethnographer. Part of this is to do with the limits of ethnographic fieldwork and the difficulties in doing 'deep' ethnographic work with adolescents which goes beyond the controlled confines of a school context. Even though I spent a great deal of time in the school, there were many parts of the informants' lives I was not able to observe. I did not attend any afterschool events and no fieldwork was conducted beyond the limits of the school. Since access of this kind would have been very difficult to obtain, I was only able to get a limited sense of who the speakers were outside of 
Banister Academy. This is not to say that the social identity which Mark constructed in the school was somehow inauthentic, but rather that his identity was specifically designed for that particular context. Nevertheless, it is possible that Mark's linguistic practices may have been influenced by something outwith Banister Academy, and that his patterns of linguistic variation may have been changed as part of an identity construction beyond Banister Academy.

\section{Conclusion}

As has been demonstrated in a number of research projects, ethnography is a powerful addition to our 'sociolinguistic toolkit'; not only does it uncover socially relevant groupings, it also provides us with an additional social lens through which we can explain concomitant patterns of linguistic variation and their role in the construction of social identity. Importantly, by focusing on the individual, we develop an extra layer of analytical description where the locally situated nature of language use is foregrounded. As Stuart-Smith and Timmins (2010: 54) highlight, 'whether at the level of processing speech from mediated signals, in the sociolinguistic alignment of incoming material, or in the locally-embedded exploitation of appropriated innovations at specific stylistic opportunities, understanding individual behaviour will always be vital'.

This chapter is one small contribution to the discussion of how finegrained linguistic variation can be understood through reference to changes in individual speakers' construction of social identity. Importantly, however, the analysis also outlined where the results were not able to be explained through reference to the ethnographic fieldwork. In this respect, school ethnographies which seek to explain the relationship between language and social identity are limited in the extent to which they can explain every aspect of speaker variation. This is not to say that ethnography is not useful, far from it, but rather, I have attempted to outline where ethnography can be helpful in developing an account of linguistic variation, as well as where it is not. Indeed, I would argue that in order for sociolinguistics to better theorise how constructions of social identity influence linguistic variation, it is vital that we understand not only the potential analytical benefits of ethnography, but also its limitations.

\section{Notes}

* Thanks to Lauren Hall-Lew for her thoughts and comments on drafts of this chapter.

1. All names given in the fieldwork are pseudonyms.

2. Although it is certainly the case that 'open-ended' questionnaires are one way of circumventing this. 
3. It is also important to note that speakers construct different ways of doing young and old, male and female, working class and middle class, and so on.

4. This is not to say, however, that quantitative approaches cannot be used in ethnographic research.

5. See Aunger (1995) for a treatment of the 'ethnography as science' question.

6. See Lawson $(2009,2011)$ for further information on the Schoolie and 'Ned' CofPs.

7. Normalisation is a process which removes physiological differences across speakers (see Watt, Fabricus and Kendall 2011 for more information).

\section{References}

Agar, Michael (1996). The Professional Stranger. Bingley: Emerald Group Publishing. Alam, Farhana (2007). Language and identity in 'Glaswasian' adolescents. Unpublished MLitt dissertation. Glasgow, UK: University of Glasgow.

Alam, Farhana and Stuart-Smith, Jane (2011). Identity and ethnicity in /t/ in GlasgowPakistani high-school girls. In Wai-Sum Lee and Eric Zee (eds), Proceedings of the XVII International Conference of Phonetic Sciences, 216-19. Hong Kong.

Atkinson, Paul and Hammersley, Martyn (2007). Ethnography: Principles in Practice. London: Routledge.

Aunger, Robert (1995). On ethnography: Storytelling or science? Current Anthropology, 36 (1): 97-130.

Barrett, Rusty (1998). Markedness and style-switching in performances by African American drag queens. In Carol Myers-Scotton (ed.), Codes and Consequences: Choosing Linguistic Varieties, 139-61. Oxford: Oxford University Press.

Boersma, Paul and Weenink, David (2013). Praat: Doing Phonetics by Computer [Computer program]. Version 5.3.42, retrieved 13 March 2013 from http://www. praat.org/.

Bourgois, Philippe (2003). In Search of Respect: Selling Crack in El Barrio. Cambridge: Cambridge University Press.

Bowie, David (2010). The aging voice: Changing identity over time. In Carmen Llamas and Dominic Watt (eds), Language and Identities, 55-66. Edinburgh. Edinburgh University Press.

Brannen, Mary Yoko (2011). Using multiple case studies to generalize from ethnographic research. In Rebecca Piekkari and Catherine Welch (eds), Rethinking the Case Study in International Business and Management Research, 124-45. Cheltenham: Edward Elgar Publishing.

Brewer, John (2000). Ethnography. Buckingham: Open University Press.

Bucholtz, Mary (1997). 'Why be normal?': Language and identity practices in a community of nerd girls. Language in Society, 28 (2): 203-23.

Bucholtz, Mary and Hall, Kira (2005). Identity and interaction: A sociocultural linguistic approach. Discourse Studies, 7 (4): 585-614.

Bucholtz, Mary and Hall, Kira (2008). All of the above: New coalitions in sociocultural linguistics. Journal of Sociolinguistics, 12 (4): 401-31.

Cameron, Deborah (2005). Language, gender and sexuality: Current issues and new directions. Applied Linguistics, 26 (4): 482-502.

Chomsky, Noam (1965). Aspects of the Theory of Syntax. Boston: Massachusetts Institute of Technology Press.

Clark, Lynn (2009). Variation, change and the usage-based approach. Unpublished PhD thesis. Edinburgh, UK: University of Edinburgh. 
Clark, Lynn and Trousdale, Graeme (2009). Exploring the role of token frequency in phonological change: Evidence from TH-fronting in east-central Scotland. English Language and Linguistics, 13 (1): 33-55.

Duranti, Alessandro (2003). Language as culture in US anthropology: Three paradigms. Current Anthropology, 44 (3): 323-35.

Drummond, Rob (2011). Glottal variation in /t/ in non-native English speech: Patterns of acquisition. English World-Wide, 32 (3): 280-308.

Eckert, Penelope (2000). Linguistic Variation as Social Practice: The Linguistic Construction of Identity in Belten High. Oxford: Blackwell.

Eckert, Penelope (2005). Variation, convention, and social meaning. Paper presented at the 34th Annual Meeting of the Linguistic Society of America. Oakland, California, 6-9 January 2005.

Eckert, Penelope and McConnell-Ginet, Sally (1992). Think practically and look locally: Language and gender as community-based practice. Annual Review of Anthropology, 21: 461-90.

Eckert, Penelope and McConnell-Ginet, Sally (1995). Constructing meaning, constructing selves: Snapshots of language, gender, and class from Belten High. In Kira Hall and Mary Bucholtz (eds), Gender Articulated: Language and the Socially Constructed Self, 459-507. London: Routledge.

Eckert, Penelope and McConnell-Ginet, Sally (2003). Language and Gender. Cambridge: Cambridge University Press.

Eckert, Penelope and Podesva, Robert J. (2011). Sociophonetics and sexuality: Toward a symbiosis of sociolinguistics and laboratory phonology. American Speech, 86 (1): 6-13.

Eckert, Penelope and Wenger, Etienne (2005). Communities of practice in sociolinguistics: What is the role of power in sociolinguistic variation? Journal of Sociolinguistics, 9 (4): 582-9.

Eustace, Elizabeth (2012). Speaking allowed? Workplace regulation of regional dialect. Work, Employment and Society, 26 (2): 331-48.

Field, Andy (2009). Discovering Statistics Using SPSS. London: SAGE Publications.

Forsythe, Diana (1999). 'It's just a matter of common sense': Ethnography as invisible work. Computer Supported Cooperative Work, 8 (1): 127-45.

Geertz, Clifford (1973). Thick description: Toward an interpretative theory of culture. In Chris Jenks (ed.), Culture: Critical Concepts in Sociology, 173-96. London: Routledge.

Gumperz, John and Hymes, Dell (eds) (1986). Directions in Sociolinguistics: The Ethnography of Communication. New York: Holt, Rhinehart and Winston.

Hall, Kira (2003). Exceptional speakers: Contested and problematized gender identities. In Miriam Meyerhoff and Janet Holmes (eds), Handbook of Language and Gender, 352-80. Oxford: Blackwell.

Herbert, Steve (2000). For ethnography. Progress in Human Geography, 24 (4): 550-68.

Hymes, Dell (1964). Introduction: Towards ethnographies of communication. American Anthropologist, 66 (6): 1-34.

Hymes, Dell (1974). Foundations in Sociolinguistics: An Ethnographic Approach. Philadelphia: University of Pennsylvania Press.

Johnson, Daniel Ezra (2009). Getting off the GoldVarb standard: Introducing Rbrul for mixed-effects variable rule analysis. Language and Linguistics Compass, 3 (1): 359-83.

Johnston, Paul (1997). Regional variation. In Charles Jones (ed.), The Edinburgh History of the Scots Language, 433-513. Edinburgh: Edinburgh University Press.

Labov, William (1963). The social motivation of a sound change. Word, 19: 273-309. 
Labov, William (1966). The Social Stratification of English in New York City. Washington, DC: Center for Applied Linguistics.

Lambert, Kirsten, Farhana Alam and Jane Stuart-Smith (2007). Investigating British Asian accents: Studies from Glasgow. In Jurgen Trouvain and William Barry (eds), Proceedings of the 16th International Conference of Phonetic Sciences, 1509-12. Saarbrücken.

Lave, Jean and Wenger, Etienne (1991). Situated Learning: Legitimate Peripheral Participation. Cambridge: Cambridge University Press.

Lawson, Robert (2009). Constructions of social identity among adolescent males in Glasgow. Unpublished PhD thesis. Glasgow, UK: University of Glasgow.

Lawson, Robert (2011). Patterns of linguistic variation among Glaswegian adolescent males. Journal of Sociolinguistics, 15 (2): 226-55.

Lawson, Robert (2013). The construction of 'tough' masculinity: Negotiation, alignment and rejection. To appear in Gender and Language, 7 (3).

Lawson, Robert (forthcoming). 'Don't even $[\theta / \mathrm{f} / \mathrm{h}]$ ink aboot it': An ethnographic investigation of social meaning, social identity and $(\theta)$ variation in Glasgow. To appear in English World-Wide, 35 (1).

LeCompte, Margaret and Schensul, Jean (2010). Designing and Conducting Ethnographic Research: an Introduction. Lanham, Md: AltaMira Press.

McConnell-Ginet, Sally (2008). Words in the world: How and why meanings can matter. Language, 84 (3): 497-527.

McEwan-Fujita, Emily (2010). Sociolinguistic ethnography of Gaelic communities. In Moray Watson and Michelle Macleod (eds), The Edinburgh Companion to the Gaelic Language, 172-217. Edinburgh: Edinburgh University Press.

Madden, Raymond (2010). Being Ethnographic: A Guide to the Theory and Practice of Ethnography. London: SAGE Publications.

Malinowski, Bronislaw (1922 [1984]). Argonauts of the Western Pacific. Long Grove, Ill.: Waveland Press.

Mendoza-Denton, Norma (2008). Homegirls: Language and Cultural Practices among Latina Youth Gangs. London: Wiley-Blackwell.

Moore, Emma (2003). Learning style and identity: A sociolinguistic analysis of a Bolton high school. Unpublished PhD thesis. Manchester, UK: University of Manchester.

Moore, Emma (2010). Communities of practice and peripherality. In Carmen Llamas and Dominic Watt (eds), Language and Identities, 123-33. Edinburgh: Edinburgh University Press.

Nance, Claire (2013). Phonetic variation, sound change, and identity in Scottish Gaelic. Unpublished PhD thesis. Glasgow, UK: University of Glasgow.

Pels, Peter (1997). The anthropology of colonialism: Culture, history, and the emergence of western governmentality. Annual Review of Anthropology, 26: 163-83.

Podesva, Robert J. (2007). Phonation type as a stylistic variable: The use of falsetto in constructing a persona. Journal of Sociolinguistics, 11 (4): 478-504.

Rampton, Ben (2007). Neo-Hymesian linguistic ethnography in the United Kingdom. Journal of Sociolinguistics, 11 (5): 584-607.

Rengert, George (1997). Review of Herbert, Steve (1997). Policing Space: Territoriality and the Los Angeles Police Department. Minnesota: University of Minnesota Press. Urban Geography, 18 (5): 468-70.

Sankoff, Gillian and Blondeau, Hélène (2007). Language change across the lifespan: /r/ in Montreal French. Language, 83 (3): 560-88. 
Shaw, Sylvia (2009-2011). Gender and linguistic participation in the devolved Parliaments of the UK. Economic and Social Research Council Grant number RES-000-22-3792.

Smith-Christmas, Cassie (2012). I've lost it here de a bh' agam: Language shift, maintenance, and code-switching within a bilingual family. Unpublished PhD thesis. Glasgow, UK: University of Glasgow.

Stuart-Smith, Jane and Timmins, Claire (2010). The role of the individual in language variation and change. In Carmen Llamas and Dominic Watt (eds), Language and Identities, 39-54. Edinburgh: Edinburgh University Press.

Tagliamonte, Sali (2006). Analysing Sociolinguistic Variation. Cambridge: Cambridge University Press.

Thomson, Alexander (2012). A communicative ethnography of speakers of the Shetlandic dialect. Poster presented at the 112th American Anthropological Association Meeting. San Francisco, California, 14-18 November 2012.

Trudgill, Peter (1974). The Social Differentiation of English in Norwich. Cambridge: Cambridge University Press.

Watt, Dominic, Anne Fabricius and Tyler Kendall (2011). Vowels, normalization and plotting. In Marianna Di Paolo and Malcah Yaeger-Dror (eds), Sociophonetics: A Student's Guide, 107-18. London: Routledge.

Wells, John (1982). Accents of English 1: An Introduction. Cambridge: Cambridge University Press.

Wilson, Nick (2007). Leading through language. An analysis of the relational practice of male leaders through ethnographic engagement. Unpublished MSc dissertation. Edinburgh, UK: University of Edinburgh. 